\title{
Contribution of the physical environment to socioeconomic gradients in walking in the Whitehall II study
}

\author{
Triantafyllos Pliakas $^{\mathrm{a}, *}$, Paul Wilkinson ${ }^{\mathrm{b}, 1}$, Cathryn Tonne ${ }^{\mathrm{b}, 2}$ \\ ${ }^{a}$ Department of Health Services Research and Policy, Faculty of Public Health and Policy, London School of Hygiene E Tropical Medicine, 15-17 Tavistock \\ Place, London WC1H 9SH, United Kingdom \\ ${ }^{\mathrm{b}}$ Department of Social and Environmental Health Research, Faculty of Public Health and Policy, London School of Hygiene E Tropical Medicine, 15-17 \\ Tavistock Place, London WC1H 9SH, United Kingdom
}

\section{A R T I C L E I N F O}

\section{Article history:}

Received 28 July 2013

Received in revised form

13 February 2014

Accepted 19 February 2014

\section{Keywords:}

Walking

Socioeconomic status

Physical environment

Objective measures

Compact neighbourhoods

\begin{abstract}
A B S T R A C T
Socioeconomic gradients in walking are well documented but the underlying reasons remain unclear. We examined the contribution of objective measures of the physical environment at residence to socioeconomic gradients in walking in 3363 participants (50-74 years) from the Whitehall II study (20022004). Individual-level socioeconomic position was measured as most recent employment grade. The contribution of multiple measures of the physical environment to socioeconomic position gradients in self-reported log transformed minutes walking/week was examined by linear regression. Objective measures of the physical environment contributed only to a small extent to socioeconomic gradients in walking in middle-aged and older adults living in Greater London, UK. Of these, only the number of killed and seriously injured road traffic casualties per $\mathrm{km}$ of road was predictive of walking. More walking in areas with high rates of road traffic casualties per $\mathrm{km}$ of road may signal an effect not of injury risk but of more central locations with multiple destinations within short distances ('compact neighbourhoods'). This has potential implications for urban planning to promote physical activity.
\end{abstract}

(c) 2014 The Authors. Published by Elsevier Ltd. This is an open access article under the CC BY license (http://creativecommons.org/licenses/by/3.0/).

\section{Introduction}

Walking is the most popular, accessible, and sustainable form of physical activity (Lee and Buchner, 2008). Its benefits for health have been well documented (World Health Organization, 2010). But it has been in decline in many countries. In Great Britain the average distance walked per person per year for transport purposes fell from 255 miles in 1975/76 to 187 miles in 2011 (Department for Transport, 2012). Reversing this trend and helping to increase walking as part of daily routine, could make an important contribution to overall physical activity levels and help reduce the risk of several non-communicable diseases (NCDs) (Lee and Buchner, 2008; World Health Organization, 2010) and the associated costs to the National Health Services (Jarrett et al., 2012). Identifying factors that increase regular walking and improve the walkability of neighbourhoods, especially among middle- and older-aged adults living in urban settings, is vital to addressing healthy aging (Kamphuis et al., 2009; Li et al., 2008).

\footnotetext{
* Corresponding author. Tel.: +44207927 2380.

E-mail addresses: triantafyllos.pliakas@lshtm.ac.uk (T. Pliakas), paul.wilkinson@lshtm.ac.uk (P. Wilkinson), cathryn.tonne@lshtm.ac.uk (C. Tonne).

${ }^{1}$ Tel.: +44207927 2444 .

2 Tel.: +44207927 2446 .
}

This is especially true for those from lower socio-economic position (SEP) who are generally observed to have lower levels of overall physical activity than those from higher SEP, irrespective of the SEP indicator used (Ball et al., 2007; Chief Medical Officers of England, Scotland, Wales, and Northern Ireland, 2011; Hillsdon et al., 2008). These patterns are consistent with socioeconomic gradients in many health outcomes and represent a key pathway through which SEP affects health (Ball et al., 2007). However, the socioeconomic gradient in walking is less clear (Cerin et al., 2009).

There is increasing evidence that neighbourhood environments may affect, at least in part, individual's physical activity and walking behaviours. Several environmental measures, both objective and perceived, have been identified as important environmental correlates of walking in adults. However, most studies in this area have been carried out in the US and Australia (Bauman and Bull, 2007; Jones et al., 2007; Ogilvie et al., 2008) and the physical environment as well as walking patterns in Europe differ considerably (Bassett et al., 2008; Foster et al., 2009; Jones et al., 2007; Macintyre, 2007; Spittaels et al., 2009). In England, research on the environmental determinants of walking in adults is expanding (Dalton et al., 2013; Foster et al., 2009, 2004; Mytton et al., 2012; Panter et al., 2013; Panter and Jones, 2008; Poortinga, 2006). These studies build up the evidence base on the links between the physical environment and walking. However, the degree to which characteristics of the physical environment 
explain socio-economic variations in walking remains unclear. Studies elsewhere have used social-ecological models to identify personal, physical and social environmental characteristics as potential explanatory factors (Annear et al., 2009; Ball et al. 2007; Cerin et al., 2009; Kamphuis et al., 2009; Ogilvie et al., 2008; Turrell et al., 2013). Social-ecological models of behaviour suggest that human behaviour is influenced by the interaction between the individual and the social and physical environment (Cerin et al., 2009; Giles-Corti and Donovan, 2002). The analysis presented in this paper tries to help fill in this gap by focusing on the physical environment using objective measures around the place of residence.

Our aim was to investigate the degree to which such physical environment variables could explain individual-level socioeconomic gradients in total minutes walking per week in middleaged and older adults living in London, UK.

\section{Methods}

\subsection{Study population and design}

We used data from the Whitehall II study, an occupational cohort of 10,308 London civil servants first recruited to the Whitehall study in 1985-1988 (Marmot and Brunner, 2005). Of these, 6914 (67.1\%) participated in phase 7 in 2002-2004 and 3654 had their postcode within the M25 motorway. We excluded 45 participants, whose postcodes were not classified as residential using the Office for National Statistics Postcode Directory and 246 participants that had missing or invalid data on walking $(n=221)$, individual-level SEP $(n=22)$ and environmental factors $(n=3)$ leaving a total of 3363 participants. Ethical approval was provided by the London School of Hygiene and Tropical Medicine ethics committe (\#5410).

\subsection{Walking data}

Participants completed a modified version of the previously validated Minnesota leisure-time physical activity questionnaire (Taylor et al., 1978) on their activities at work and in their free time. Self reported measures of walking were based on the following question: on average, for how many minutes did you walk outside your home/workplace on each weekday and each weekend day in the past week. Total minutes per week were calculated by adding the daily sub-totals.

\subsection{Socioeconomic position and covariates}

Data on SEP were available at the individual and area-level. Individual-level data included current/most recent employment grade at the civil service, classified into six groups: clerical/support (lowest), executive, higher and senior executive officer, and unified grade (UG) 7 and UG 1-6 (highest), total household income, and educational attainment (measured as the highest level of education achieved). Area-level data, available at the lower layer super output area (LSOA), included the income score extracted from the income domain of the Index of Multiple Deprivation 2004 (Noble et al., 2004). LSOAs are administrative boundaries with a minimum population of 1000 residents and 400 households and a mean population of 1500 based on 2001 Census population figures (Noble et al., 2004). We selected employment grade as the focus of our analysis as this variable exhibited the most consistent and largest gradient in walking. We included the area-level SEP as a covariate in selected analyses.

Socio-demographic variables included sex, age, ethnicity (white $v s$ other), and labour market status (remaining in civil service vs working outside civil service, not working - retired, out of work and not working - longterm sick). These variables have been consistently found to be associated with walking and different types of physical activity and were treated as a priori confounders (The Chief Medical Officer, 2004). Health variables included body mass index (BMI; $\mathrm{kg} / \mathrm{m}^{2}$ ), overall physical activity levels (light vs moderate and high activity), smoking status and number of comorbidities. We generated a composite indicator of multi-morbidity based on whether an individual had been diagnosed with diabetes or stroke, or was on cortico-steroids, ACE inhibitors, beta blockers or lipid lowering medications. We used this measure as a proxy measure of self-limiting health status.

\subsection{Objective measures of the physical environment}

Measures of the physical environment were generated using ArcGIS 10 (ESRI, 2010) at two spatial scales: (i) the LSOA and (ii) areas within $800 \mathrm{~m}$ of the centroid of the postcode of residence (there are approx. 14 households/UK residential postcode). We used Euclidean distances that represent an area within approximately a 10 min walk from home and is comparable to that used in other studies (Coombes et al., 2010; Dalton et al., 2013). A total of 40 environmental variables were examined in the following nine attribute categories: crime, proximity to services, green space, road/ traffic density, land use, population density, road traffic injuries (RTIs), air pollution, and public transport provision. See Table 1 for definitions and data sources.

\subsection{Statistical methods}

We used regression modelling to estimate the relationship between individual-level SEP and walking and the influence of the physical environment. Values for total minutes walking were positively skewed and were log transformed. For ease of interpretation, regression coefficients $(\beta)$ were converted into per cent increase in average minutes walking using the formula $[\exp (\beta)-1]$ 100. Associations for environmental variables are presented as the per cent change in walking minutes per week for an increase from the 5 th to the 95th centile of the explanatory variable.

To simplify analysis given highly correlated variables, we included in the regression models a single variable per attribute category shown in Table 1 . To select these variables we used the 'all subsets' approach implemented in the Furnival-Wilson leaps-and-bounds algorithm, which uses five information criteria for selection: the smallest value of Akaike Information Criterion (AIC), corrected AIC $\left(\mathrm{AIC}_{\mathrm{C}}\right)$, and the Bayesian Information Criterion; the largest value of $R_{\mathrm{ADj}}^{2}$; and a value of Mallows's $C_{\mathrm{p}}$ that is close to the number of predictors in the models +1 or the smallest among the other Mallows's $C_{\mathrm{p}}$ values (Lindsey and Sheather, 2010). The SEP variables and $a$ priori confounders were fixed throughout the process.

The associations between walking and individual-level SEP were examined using various models of co-variate adjustment, broadly using the theoretical frameworks and approaches used in previous studies (Giles-Corti and Donovan, 2002; Ogilvie et al., 2008). Results are presented without adjustment (Model 1); adjustment for a priori confounders only (Model 2); and adjustment for a priori confounders and the objectively measured physical environmental variables (one per attribute) entered simultaneously into the model (Model 3). Clustering of individuals within LSOAs was taken into account using robust standard errors.

Sensitivity analyses were performed to assess the robustness of the models. These were based on adjusting for the effect of health factors (BMI, co-morbidities and smoking), the exclusion of longterm ill (time spent walking independent of the physical environment due to physical impairment), the use of alternative individual-level SEP indicators (income and education), a priori 
Table 1

Data sources and definitions of the local (neighbourhood) environment using objective measures of the physical environment.

\begin{tabular}{|c|c|c|}
\hline Attribute & Definitions & Year (Source) \\
\hline \multicolumn{3}{|c|}{ LSOA-level variables } \\
\hline Crime (1) & Crime score & 2002-2003 (IMD 2004 NS-ONS) (Noble et al., 2004) \\
\hline $\begin{array}{l}\text { Proximity to } \\
\text { services (2) }\end{array}$ & $\begin{array}{l}\text { Population weighted average road distance }(\mathrm{km}) \text { to a food store } \\
\text { Population weighted average road distance }(\mathrm{km}) \text { to a post office }\end{array}$ & \\
\hline Green space (7) & $\begin{array}{l}\text { Area of public green space and area of domestic gardens (expressed in } 1000 \mathrm{~m}^{2} \text { ) } \\
\text { Percentages of public green space and public green space per } 1000 \text { population } \\
\text { Provision of public green space per capita ( } \mathrm{m}^{2} / \text { person) } \\
\text { Percentages of domestic gardens and domestic gardens per } 1000 \text { population }\end{array}$ & $\begin{array}{l}2005 \text { (GLUDS NS-ONS) (Department for } \\
\text { Communities and Local Government, 2007) }\end{array}$ \\
\hline $\begin{array}{l}\text { Road/traffic } \\
\text { density (3) }\end{array}$ & $\begin{array}{l}\text { Area allocated to transport (expressed in } 1000 \mathrm{~m}^{2} \text { of roads, paths and rail) } \\
\text { Percentages of area allocated to transport (roads, paths and rail) and area allocated to roads }\end{array}$ & \\
\hline Land use (4) & $\begin{array}{l}\text { Herfindahl-Hirschmann Index (HHI })^{\mathrm{a}} \\
\mathrm{HHI}=\Sigma\left(P_{i} 100\right)^{2} \text {, where } P \text { is the proportion of each land type and } i \text { is the land type } \\
\text { Spatial entropy score (SENS) } \\
-\Sigma\left(P_{i} \ln P_{i}\right) / \ln N \text {, where } P \text { is the proportion of each land type, } i \text { is the land type and } N \text { is the } \\
\text { number of land types } \\
\text { Percentages of non-residential buildings and residential buildings }\end{array}$ & \\
\hline $\begin{array}{l}\text { Population } \\
\text { density (2) }\end{array}$ & Crude $\left(\right.$ per $\mathrm{km}^{2}$ ) and smoothed (per $\mathrm{km}^{2}$ ) (based on $10 \mathrm{~km}$ buffer) & 2001 (NS-ONS) (Office for National Statistics, 2001) \\
\hline \multicolumn{3}{|c|}{ Postcode-level variables (within an area buffer of $800 \mathrm{~m}$ unless otherwise stated) } \\
\hline $\begin{array}{l}\text { Road traffic } \\
\text { injuries (RTIs) } \\
(8)\end{array}$ & $\begin{array}{l}\text { Number of all RTIs and RTIs involving pedestrians and/or cyclists only } \\
\text { Number of KSI and KSI involving pedestrians and/or cyclists only } \\
\text { RTIs per km of road and RTIs involving pedestrians and/or cyclists only per km of road } \\
\text { KSI per km of road and KSI involving pedestrians and/or cyclists only per km of road }\end{array}$ & $\begin{array}{l}2003 \text { (Road accident data, DfT) (Department for } \\
\text { Transport, Road Accident Statistics Branch, 2009) }\end{array}$ \\
\hline Air pollution ${ }^{\mathrm{c}}(3)$ & Annual average $\mathrm{NO}_{2}(\mathrm{ppb})$, Annual average $\mathrm{NO}_{\mathrm{x}}(\mathrm{ppb})$ and Annual average $\mathrm{PM}_{10}\left(\mu \mathrm{g}\right.$ per $\left.\mathrm{m}^{3}\right)$ & 2003 (MRC-HPA, KCL) (Kelly et al., 2011) \\
\hline $\begin{array}{l}\text { Access to public } \\
\text { transport (APT) } \\
\text { (4) }\end{array}$ & $\begin{array}{l}\text { Number of bus and coaches stops and stations } \\
\text { Number of bus and coaches stops and stations per km of road } \\
\text { Number of bus, coaches, train and metro stops and stations } \\
\text { Number of bus, coaches, train and metro stops and stations per km of road }\end{array}$ & $\begin{array}{l}2008(\text { NaPTAN, DfT })^{\mathrm{d}} \text { (Department for Transport, } \\
\text { 2013) }\end{array}$ \\
\hline $\begin{array}{l}\text { Road/traffic } \\
\text { density (6) }\end{array}$ & $\begin{array}{l}\text { Length of a-roads }(\mathrm{m}) \text {, length of local roads }(\mathrm{m}) \text { and length of pedestrianised street }(\mathrm{m}) \\
\text { Length of local roads as a proportion of all roads }(\%) \text { and a-roads as a proportion of all roads } \\
(\%) \\
\text { Total length of road network (a-road, b-road, primary road, minor road, motorway, local } \\
\text { street, pedestrianised street, private road with public access and road tunnel) (m) }\end{array}$ & $\begin{array}{l}2010 \text { (Ordnance Surve OpenData) (Ordnance Survey, } \\
\text { 2013) }\end{array}$ \\
\hline
\end{tabular}

Number of environmental variables per attribute category in parentheses.

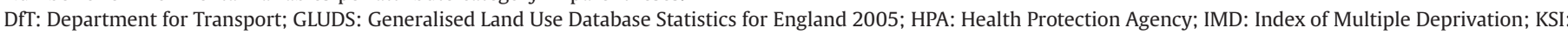

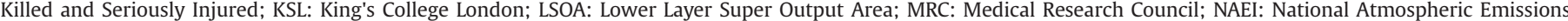

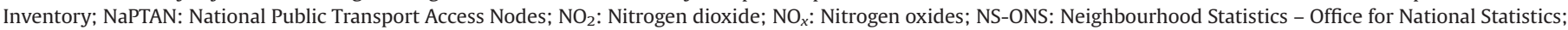
NSPD: National Statistics Postcode Directory; OS: Ordnance Survey; PM: Particulate matter.

${ }^{a}$ Higher values represent less diversity in terms of land use.

${ }^{\mathrm{b}}$ Measure of evenness and ranges from 0 to 1 with higher values representing a more heterogeneous and evenly mixed land-use per LSOA.

c $20 \mathrm{~m}^{2}$ grid resolution.

d Restricted to bus, coaches, train and metro stops and stations that were active and created before 2008.

selected environmental variables based on previous studies in the UK, and analyses stratifying walking during weekdays or weekend days. All analyses were performed in Stata 12.1.

\section{Results}

Study participants were, on average, 61 years of age, and the majority remained working in or outside civil service (52.7\%). Participants walked a total of $6 \mathrm{~h} /$ week, with slightly more walking on weekend than week days (50 vs $45 \mathrm{~min} /$ day). White males with higher SEP were over-represented in this sample. Compared to participants living within the M25 but not included in the analysis, this group was younger (62.7 vs 61.0 ), was composed of more males (48.5\% vs $65.3 \%$ ) and had fewer participants from the lower SEP group (33.6\% vs 14.6\%), retired (53.6\% vs $41.2 \%$ ) and coming from other ethnic background (23.4\% vs $13.1 \%$ ) (all $p<0.001$, data not shown).

Characteristics of participants by SEP are summarised in Table 2. Compared to the high SEP group, lower SEP participants were older and were less likely to be male, white ethnicity, or working in or outside civil service. This group had a higher BMI, higher prevalence of co-morbidities and current smokers. In terms of physical activity, lower SEP participants, classified as clerical and support staff, spent, on average, more time on walking than higher SEP participants (346 vs $310 \mathrm{~min} /$ week) with this type of activity comprising a greater proportion of total moderate activities. However, lower SEP participants reported spending more hours being sedentary or doing light activities, and less time doing moderate/vigorous activities.

With respect to the physical environment, people from lower SEP lived in areas that had higher road and population density, air pollution, number of killed and seriously injured per $\mathrm{km}(\mathrm{KSI} / \mathrm{km})$ of road, and number of public transport stops and stations (bus, coaches, train and metro). They also lived in areas that were more mixed in terms of land use with a higher density of non-residential buildings, lower density of public green space and a lower average road distance to a super market or convenience store.

There was no clear evidence of association between SEP and walking in the unadjusted model (Table 3, Model 1) but when adjusted for a priori confounders there was evidence that people from lower SEP groups walked more minutes/week than those from higher SEP groups (Table 3, Model 2). Similarly, walking patterns remained the same irrespective of the SEP indicator used (data not shown). Non-white ethnic background, working outside civil service and being long-term sick (compared to remaining in civil service) were associated with a significant decrease in walking.

When investigating the association of environmental variables with walking, we observed that each of the following environmental 
Table 2

Characteristics of participants of the Whitehall II study and their residential environment according to socio-economic position (SEP) ( $n=3363$ ).

\begin{tabular}{|c|c|c|c|c|c|c|}
\hline & \multicolumn{2}{|l|}{ High SEP } & \multicolumn{2}{|l|}{ Medium SEP } & \multicolumn{2}{|l|}{ Low SEP } \\
\hline & UG1-UG6 & UG7 & SEO & HEO & EO & $\mathbf{C} / \mathbf{S}$ \\
\hline \multicolumn{7}{|l|}{ Socio-demographic variables } \\
\hline Age in years (mean, SD) & $61(5.9)$ & $60(5.8)$ & $60(6.1)$ & $60(6.0)$ & $62(6.1)$ & $63(6.1)$ \\
\hline Male $(\%)$ & 81.0 & 81.8 & 80.6 & 66.7 & 45.7 & 26.4 \\
\hline White ethnicity (\%) & 97.8 & 96.8 & 92.0 & 87.6 & 72.7 & 67.9 \\
\hline \multicolumn{7}{|l|}{ Labour Market Status (\%) } \\
\hline Remaining in CS $(\mathrm{n}=1110)$ & 32.4 & 35.8 & 34.7 & 34.7 & 29.1 & 31.3 \\
\hline Working outside CS $(n=661)$ & 29.0 & 22.1 & 20.0 & 18.8 & 14.3 & 8.5 \\
\hline Not working - retired $(n=1404)$ & 34.5 & 38.2 & 40.1 & 41.1 & 49.7 & 51.0 \\
\hline Out of work $(n=131)$ & 3.8 & 2.9 & 3.6 & 4.0 & 4.2 & 5.1 \\
\hline Not working - LT sick $(n=57)$ & 0.4 & 1.0 & 1.6 & 1.3 & 2.7 & 4.1 \\
\hline \multicolumn{7}{|l|}{ Health variables } \\
\hline $\operatorname{BMI}\left(\mathrm{n}=3195 ; \mathrm{kg} / \mathrm{m}^{2}\right)($ mean, SD) & $26.0(3.95)$ & $26.5(4.49)$ & $26.6(4.49)$ & $26.7(4.46)$ & $26.6(4.83)$ & $27.9(4.88)$ \\
\hline No co-morbidity (\%) & 70.9 & 71 & 69.5 & 68.4 & 64.1 & 61.8 \\
\hline Never smoker or Ex-smoker $(n=3347)(\%)$ & 93.9 & 93.7 & 90.6 & 87.3 & 89.2 & 87.4 \\
\hline \multicolumn{7}{|l|}{ Physical activity variables (mean, SD) } \\
\hline Total minutes of walking per week in past week & $310(231.3)$ & $296(240.4)$ & $326(231.8)$ & $321(208.1)$ & $329(281.6)$ & $346(288.0)$ \\
\hline Percentage of total moderate METs attributed to walking $(n=3321)$ & 66.9 & 65.9 & 68.7 & 67.4 & 74.3 & 80.2 \\
\hline $\begin{array}{l}\text { Total hours per week being sedentary or doing light intensity physical activity } \\
(\mathrm{n}=3335)^{\mathrm{a}}\end{array}$ & $5.5(4.66)$ & $5.7(4.98)$ & $6.6(5.30)$ & $7.3(5.45)$ & $8.3(5.96)$ & $7.9(5.41)$ \\
\hline Total hours per week doing moderate intensity physical activity $(\mathrm{n}=3331)^{\mathrm{b}}$ & $29.1(18.18)$ & $28.3(19.46)$ & $29.4(18.01)$ & $29.5(17.66)$ & $26.9(19.63)$ & $26.0(19.61)$ \\
\hline Total hours per week doing vigorous intensity physical activity $(n=3335)^{c}$ & $5.0(8.08)$ & $4.3(7.88)$ & $4.1(7.01)$ & $4.2(7.78)$ & $2.8(6.05)$ & $1.4(3.75)$ \\
\hline Average minutes walked on week days in last week $(n=3340)$ & $43(35.0)$ & $42(39.6)$ & $44(32.8)$ & $45(31.4)$ & $47(43.2)$ & $50(45.3)$ \\
\hline Average minutes walked on weekend days in last week $(n=3257)$ & $49(44.8)$ & $45(39.9)$ & $54(53.3)$ & $49(42.0)$ & $51(50.3)$ & $54(50.9)$ \\
\hline \multicolumn{7}{|l|}{ LSOA-level environmental variables (mean, SD) } \\
\hline Crime score & $0.0(0.76)$ & $-0.1(0.74)$ & $-0.1(0.72)$ & $0.0(0.73)$ & $0.2(0.71)$ & $0.2(0.74)$ \\
\hline Density of non-residential buildings (\%) & $4.3(5.89)$ & $3.9(5.65)$ & $3.9(4.84)$ & $4.1(4.65)$ & $4.6(5.23)$ & $6.1(7.08)$ \\
\hline Herfindahl-Hirschmann Index (HHI) & $\begin{array}{l}4316 \\
(1313.0)\end{array}$ & $\begin{array}{l}4367 \\
(1297.2)\end{array}$ & $\begin{array}{l}4301 \\
(1275.8)\end{array}$ & $\begin{array}{l}4220 \\
(1240.5)\end{array}$ & $\begin{array}{l}4079 \\
(1200.1)\end{array}$ & $\begin{array}{l}3900 \\
(1244.3)\end{array}$ \\
\hline Density of road network (\%) & $15.2(7.24)$ & $14.5(6.43)$ & $14.9(6.10)$ & $15.0(6.01)$ & $15.8(6.13)$ & $17.3(6.88)$ \\
\hline Density of public green space (\%) & $25.0(23.70)$ & $26.1(23.75)$ & $23.7(21.90)$ & $23.5(21.35)$ & $23.7(21.29)$ & $21.0(19.44)$ \\
\hline Population weighted average road distance to a food store $(\mathrm{km})$ & $1.0(0.68)$ & $1.0(0.71)$ & $1.0(0.63)$ & $1.0(0.54)$ & $1.0(0.51)$ & $0.9(0.57)$ \\
\hline Population density per $\mathrm{km}^{2}$ & $\begin{array}{l}5945 \\
(4753.2)\end{array}$ & $\begin{array}{l}5500 \\
(4362.7)\end{array}$ & $\begin{array}{l}5839 \\
(4122.4)\end{array}$ & $\begin{array}{l}6062 \\
(3988.7)\end{array}$ & $\begin{array}{l}6627 \\
(4711.2)\end{array}$ & $\begin{array}{l}7856 \\
(5515.1)\end{array}$ \\
\hline \multicolumn{7}{|l|}{ Postcode-level environmental variables ${ }^{\mathrm{d}}$ (mean, SD) } \\
\hline Annual average $\mathrm{NO}_{2}$ concentration (ppb) $\left(20 \mathrm{~m}^{2}\right.$ grid resolution) & $40.0(6.69)$ & $38.8(6.23)$ & $38.5(5.33)$ & $39.1(5.49)$ & $39.9(5.68)$ & $41.3(6.59)$ \\
\hline $\mathrm{KSI} / \mathrm{km}$ of road & $0.25(0.201)$ & $0.23(0.183)$ & $0.23(0.175)$ & $0.24(0.179)$ & $0.26(0.191)$ & $0.32(0.221)$ \\
\hline Number of KSI & $6.7(6.98)$ & $6.1(6.56)$ & $6.0(6.04)$ & $6.3(6.02)$ & $7.0(6.54)$ & $9.3(8.67)$ \\
\hline APT & $35(18.7)$ & $32(17.3)$ & $32(16.6)$ & $33(14.5)$ & $34(16.5)$ & $39(20.4)$ \\
\hline Length of a-road (m) & $\begin{array}{l}1928 \\
(1757.5)\end{array}$ & $\begin{array}{l}1873 \\
(1686.4)\end{array}$ & $\begin{array}{l}1810 \\
(1859.1)\end{array}$ & $\begin{array}{l}1843 \\
(1653.0)\end{array}$ & $\begin{array}{l}2021 \\
(1834.1)\end{array}$ & $\begin{array}{l}2320 \\
(2174.3)\end{array}$ \\
\hline
\end{tabular}

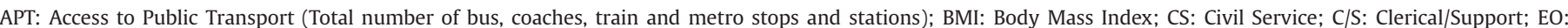

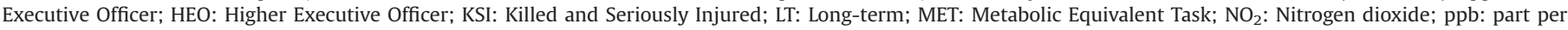
billion; SD: Standard Deviation; SEO: Senior Executive Office; SEP: Socio-Economic Position; UG: Unified Grade.

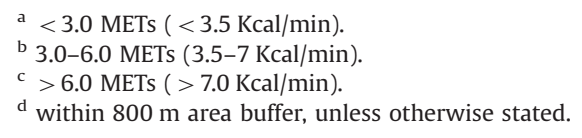

Table 3

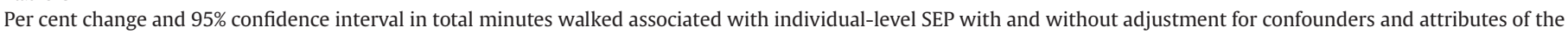
physical environment $(n=3363)$.

\begin{tabular}{|c|c|c|c|c|c|c|}
\hline & Model 1 & & Model 2 & & Model 3 & \\
\hline \multicolumn{7}{|l|}{ Main exposure } \\
\hline UG1-UG6 (reference) & - & - & - & - & - & - \\
\hline UG7 & -7.0 & -13.9 to 0.5 & -6.8 & -13.7 to 0.7 & -6.4 & -13.4 to 1.2 \\
\hline Senior Executive Officer & 1.9 & -6.4 to 10.9 & 3.9 & -4.5 to 13.0 & 4.1 & -4.4 to 13.3 \\
\hline Higher Executive Officer & 1.4 & -6.4 to 9.9 & 5.2 & -2.9 to 13.9 & 5.5 & -2.6 to 14.4 \\
\hline Executive Officer & -0.4 & -8.2 to 8.0 & 9.9 & 0.7 to 19.9 & 9.8 & 0.6 to 19.9 \\
\hline Clerical/Support & 1.9 & -6.9 to 11.6 & 15.1 & 3.9 to 27.5 & 13.0 & 1.9 to 25.2 \\
\hline$P$ for linear trend & & 0.280 & & 0.0003 & & 0.0009 \\
\hline \multicolumn{7}{|l|}{ A priori confounders } \\
\hline Sex (Female) & & & -3.4 & -9.2 to 2.8 & -4.5 & -10.3 to 1.6 \\
\hline Age in years & & & 0.1 & -0.6 to 0.8 & 0.1 & -0.5 to 0.8 \\
\hline Ethnicity (Other) & & & -27.7 & -33.5 to -21.3 & -28.0 & -33.8 to -21.7 \\
\hline \multicolumn{7}{|l|}{ Labour Market Status } \\
\hline \multicolumn{7}{|l|}{ Remaining in CS (reference) } \\
\hline Working outside CS & & & -10.1 & -16.8 to -2.8 & -10.6 & -17.3 to -3.3 \\
\hline
\end{tabular}




\begin{tabular}{|c|c|c|c|c|}
\hline Model 1 & Model 2 & & Model 3 & \\
\hline Not working - retired & -6.0 & -14.1 to 2.8 & -6.2 & -14.2 to 2.5 \\
\hline Out of work & 1.2 & -12.6 to 17.2 & 0.9 & -12.6 to 16.6 \\
\hline Not working - LT sick & -40.0 & -56.0 to -18.3 & -41.4 & -57.1 to -19.9 \\
\hline \multicolumn{5}{|l|}{ Environmental variables (5th-95th centile) } \\
\hline \multicolumn{5}{|l|}{ LSOA-level } \\
\hline Crime score ( -1.09 to 1.33$)$ & & & 0.3 & -9.1 to 10.6 \\
\hline Density of non-residential buildings (\%) (0.3-15.8) & & & 3.7 & -5.2 to 13.6 \\
\hline Density of road network (\%) $(4.2-26.3)$ & & & 9.7 & -8.0 to 30.9 \\
\hline Density of public green space (\%)(1.5-73.4) & & & 8.6 & -4.9 to 24.1 \\
\hline Pop weighted road $\mathrm{km}$ to foodstore $(0.33-1.91)$ & & & -0.8 & -8.1 to 7.0 \\
\hline Population density per $\mathrm{km}^{2}(715-14,815)$ & & & 3.7 & -7.8 to 16.6 \\
\hline \multicolumn{5}{|l|}{ Postcode-level } \\
\hline Annual average $\mathrm{NO}_{2}$ concentration $(\mathrm{ppb})^{\mathrm{a}}(30.55-50.38)$ & & & -11.7 & -24.9 to 3.8 \\
\hline $\mathrm{KSI} / \mathrm{km}$ of road ( $800 \mathrm{~m}$ area buffer) $(0.00-0.64)$ & & & 17.5 & 2.8 to 34.4 \\
\hline APT ( $800 \mathrm{~m}$ area buffer) $(11-64)$ & & & 3.3 & -9.3 to 17.6 \\
\hline
\end{tabular}

Model 1: Unadjusted; Model 2: Adjusted for a priori confounders; Model 3: As Model 2 and adjusted for environmental variables.

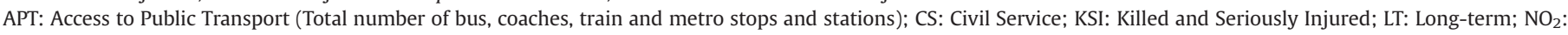
Nitrogen dioxide; ppb: part per billion; SEP: Socio-Economic Position; UG: Unified Grade.

a $20 \mathrm{~m}^{2}$ grid resolution.

variables (fitted one at a time in addition to the a priori nonenvironmental confounders) was associated with increases in walking time: density of non-residential buildings, density of road network, population density, length of a-roads, number of public transport stops and stations, number of KSI and number of $\mathrm{KSI} / \mathrm{km}$ of road. The greatest contribution to SEP gradients in walking was observed for $\mathrm{KSI} / \mathrm{km}$ of road where the gradient in the lower SEP category was attenuated from $15.1 \%$ to $13.9 \%$ (data not shown).

Inclusion of all environmental variables in addition to the nonenvironnmental a priori confounders led to only a small reduction in the SEP gradient in total minutes of walking per week (compared to a model with non-environmental a priori confounders alone), suggesting only limited influence of the physical environment on walking behaviour. Only the number of $\mathrm{KSI} / \mathrm{km}$ of road within $800 \mathrm{~m}$ of the postcode of residence was significantly associated with walking (Table 3, Model 3). Area-level SEP was not independently associated with walking and inclusion in the model did not change individual-level SEP gradients in walking (data not shown).

Our findings were relatively insensitive to the type of SEP indicator used (data not shown). In models with additional adjustment for health factors (with and without excluding longterm ill participants), population density and $\mathrm{KSI} / \mathrm{km}$ of road were both positively associated with total minutes per week of walking. Inclusion of attributes of the physical environment had some effect on the estimates of the SEP gradient in walking in models confined to week days, but not in models confined to weekend days (Web appendix Table S1, environmental variables fitted simultaneously in model).

\section{Discussion}

This study provides new insights into the determinants of SEP gradients in walking and suggests that objective measures of the physical environment have only a very limited influence on such gradients among middle aged and older adults living in the Greater London area.

Socioeconomic position is known to be one of the strongest and most consistent predictors of walking and physical activity. Our aim was to investigate whether these observed SEP gradients in walking can be explained by objective measures of the physical environment. In our main analyses, only one of the environmental variables analysed showed clear evidence of association with the total minutes of walking per week, namely the number of $\mathrm{KSI} / \mathrm{km}$ of road within $800 \mathrm{~m}$ of residence. Why this variable should show a positive association with walking is not clear, but we speculate that it is an effect not of perceptions of injury risk but of the correlation between high $\mathrm{KSI} / \mathrm{km}$ of road and city centre/local centre locations where there are multiple destinations within short distances. If there is a direct effect of a high casualty rate it seems more probable that it would dissuade walking than encourage it because of its impact on perceptions of safety (Cochrane et al., 2009). However, the KSI $/ \mathrm{km}$ of road may be a surrogate of walkable access to local shops, services and facilities (Cochrane et al., 2009; Priyantha Wedagama et al., 2006), as more casualties (and hence high $\mathrm{KSI} / \mathrm{km}$ ) can be expected on roads where both pedestrian and vehicle densities are high (Schuurman et al., 2009). This is borne out by Fig. WA1, which shows that areas and roads with high number of KSI are nearer to central London or local ('London village') centres.

This interpretation is reinforced by the results for environmental variables entered into the model one at a time that indicated (in models adjusted for a priori non-environmental confounders) positive associations with levels of walking for higher road and population density, traffic-related air pollution, number of public transport stops and stations, higher density of non-residential buildings, lower density of public green space and a lower average road distance to a super market or convenience store. These patterns suggest that they are surrogates for some other feature of the local environment, and a correlate common to all is central location (Turrell et al., 2013). This may be an important observation for urban planning to promote physical activity, as it reinforces the importance of having multiple destinations within easy walking distance.

The results of our study were robust across a range of sensitivity analyses, including the use of alternative individual-level SEP indicators. Area-level SEP did not make an independent contribution to individual-level SEP gradients in walking, which may suggest that residents of high as well as low area-level SEP may equally benefit from highly-walkable environments (Van Dyck et al., 2010). The impact of the physical environment on SEP gradients in walking was greater on week days than weekend days, suggesting that people may respond to environmental features closer to their residence more strongly than to more distant environmental qualities (GilesCorti and Donovan, 2002) on week days and the propensity to walk 
may be more strongly influenced by attributes of the physical environment outside people's local environments (Ogilvie et al., 2008) on weekend days.

Our results are also broadly consistent with previous studies that have shown that personal characteristics and attributes of the physical and social environment contribute to SEP gradients in walking and physical activity (Ball et al., 2007; Cerin et al., 2009; Giles-Corti and Donovan, 2002; Hillsdon et al., 2008; Kamphuis et al., 2009; Ogilvie et al., 2008). Two studies in Melbourne and Perth, Australia, showed that objective measures of the physical environment contributed to a small extent in explaing SEP gradients in walking indicating that personal characteristics may be equally or more important (Ball et al., 2007; Giles-Corti and Donovan, 2002). Physical environment variables identified as explaining SEP gradients in walking included street connectivity, coastal proximity and access and use of recreational facilities (Ball et al., 2007; Giles-Corti and Donovan, 2002). Our findings on the lack of an association between walking, green space and area levels of crime are also consistent with a previous study in England (Foster et al., 2009).

In our study we only found limited evidence of an association between the physical environment and walking despite the range of environmental variables used. There are a number of reasons for this. First there might be other yet unknown objectively measured environmental factors that may be stronger predictors of walking. Second, the limited environmental heterogeneity in the study area may contribute to the lack of association between the physical environment and walking. Studies carried out at the national level or in areas with contrasting environments (e.g. urban vs rural) may be able to identify which attributes of the physical environment are more important for walking (and other health behaviours). Third, there may be lack of specificity in the physical environment variables used in this study and these variables may be stronger predictors of other health or physical activity behaviours but not walking (Foster et al., 2009; Giles-Corti et al., 2005b; Ogilvie et al., 2008). These issues call for an improvement in the tools used to assess physical activity and the physical environment and the studies looking at quantifying the impact of the physical and built environment on health behaviours and outcomes. Finally, attributes of one's social and material environment not investigated here, such as social capital, social connectivity and interaction, and access to a motor vehicle, are predictive of physical activity and may be more important factors in explaining SEP gradients in walking than the physical environment (Giles-Corti and Donovan, 2002; Lopez and Hynes, 2006; Turrell et al., 2013). Furthermore, perceptions of the physical environment may more directly shape walking behaviour compared to objective measures (Ball et al., 2008) particularly in older people (Annear et al., 2009). However, individuals living in the same environment may perceive this in different ways (King et al., 2005) and objective measures more effectively quantify the impact of the physical environment on health behaviours and facilitate the translation of study results directly into intervention strategies and policies (Cummins et al., 2007; Lin and Moudon, 2010). Previous studies in England looking at how perceptions of the physical environment might influence walking are limited and inconclusive. Foster et al. (2004) found no association between perceived measures of traffic density, perceived access to leisure centres or neighbourhood aesthetics and walking. In the same study, they reported gender differences between perceived safety from crime or park/open space convenience and walking (men but not women were more likely to walk if they had a park or open space within walking distance, whereas women but not men were more likely to walk if they felt safe during the day). Although we did not investigate differences by different socio-demographic groups here, it is likely that different aspects of the physical environment may affect these groups in different ways (Foster et al., 2004; Macintyre et al., 2002; Panter and Jones, 2008) and this could be the subject of future research. Two studies failed to find any association between presence of social nuisances (vandalism/graffiti and deliberate damage to property) or distance to park and walking (Panter and Jones, 2008; Poortinga, 2006). Perceived measures of access to services and local shops have been consistently found to be related to walking (Panter and Jones, 2008; Poortinga, 2006), which provide further support to our finding that the $\mathrm{KSI} / \mathrm{km}$ of road may act as a surrogate of accessibility to services in urban areas. Finally, people reporting convenience of public transport were more likely to uptake of walking (Panter et al., 2013).

Study limitations should be considered whilst interpreting our results. These include the cross-sectional design and the reliance on self-reported measures of walking, although a recent study found that self-reported physical activity at phase 5 (1995-1996) was predictive of objectively measured physical activity at phase 9 (2008-2009) in a sub-sample of the Whitehall II participants (Hamer et al., 2012). Walking, irrespective of purpose, has important health benefits (World Health Organization, 2010), however different types of walking (transport and recreational) may have different demographic correlates (Kruger et al., 2008) and may be differentially affected by the physical environment (Ball et al., 2007; Giles-Corti et al., 2005b; Li et al., 2008). We only looked at the residential environment but much of the walking may take place as part of a journey to work or at work. Attributes of the physical environment on the way to work (or other destinations) or at work may be stronger predictors of walking or the propensity to walk (Chaix et al., 2013). External validity may be limited since our study population is not representative of the general population in England and civil service employment grades only included non-manual occupation not covering the full range of adult SEP. Uncontrolled or residual confounding can not be ruled out. For example, we were not able to adjust for car use and car ownership, which might expain some of the SEP gradient in walking, although car owneship may itself be a consequence of choice in physical activity rather than an independent effect of it. This is relevant to the issue of direction of causation which is relevant to a number of associations in this analysis (e.g. an inverse relationship between BMI and walking may be a cause or a consequence of physical (in) activity). Finally, the exclusion of low SEP participants with missing values for walking may result in selection bias. If these participants were less likely to have walked, then the individuallevel SEP gradients reported here are likely to be an overestimate of the true magnitude of SEP gradients in walking in this population (Rothman et al., 2008).

A number of methodological issues should also be discussed. A predefined use of an area, either the use of administrative or statistical boundaries or area buffers may not reflect how people perceive their local environment, particularly in relation to walking (Saelens et al., 2003; Smith et al., 2010), and may not be appropriate scales to use for different types of human activities (Macintyre et al., 2002). We also made a number of assumptions when examing the relationship between access, availability and provision of services and resources (e.g. public transport, services and green space) and real use. We were unable to directly correlate these as we did not have information on the type, quality and use of these services and resources. These information are essential and should be included in future studies (Foster et al., 2009; Giles-Corti et al., 2005a; Mitchell and Popham, 2008). Although residential self selection bias is an important consideration, results from a recent longitudinal study found that self selection was not related to changes in walking (Giles-Corti et al., 2013). Among the different ways in addressing this (Cao et al., 2009), it has been suggested that in lieu of information on self-selection, conditioning models on SEP and socio-demographic 
charactersitics is likely to address, at least partially, confounding that results from residential self-selection (Bentley et al., 2010). Alternative measures of traffic safety than what we used have been proposed to be more appropriate measures of an individual's risk to RTAs, such as a rate per population (Schuurman et al., 2009) or distance travelled (Sebert Kuhlmann et al., 2009).

This study has important strengths. The Whitehall II study is a well documented cohort study, with detailed data on individual-level SEP. We used a range of secondary datasets collected by various Governmental Departments to generate objective environmental measures. Although these datasets had a high degree of completeness we were unable to confirm their quality and validity. Except public transport stops and station and the road network, all other data were collected at approximately the same time as people were surveyed about their walking and our study is therefore unlikely to suffer from misclassification of environmental exposure due to changes in the built environment over time. This said, studies should employ neighbourhood audits, where feasible, to confirm the validity of secondary data sources. We also tested the robustness of our results in sensitivity analyses using different SEP indicators. Finally, focusing on this age group has important policy implcations due to the aging population and the effect that this may have on healthcare expenditure, allocation and utilisation. Understanding which attributes of the physical environment can influence physical activity behaviour in this age group can help reduce the economic and social burden of NCDs and improve individual quality of life (Li et al., 2008).

In conclusion, we found that objective measures of the physical environment explain SEP gradients in walking to only limited degree, with the impact being greater in week days than weekend days. In recent years, promoting active travel (i.e. walking and cycling) and the need to provide a supportive environment have been the focus of policy agendas in relation to health, transport and climate change (British Medical Association, 2012; Chief Medical Officers of England, Scotland, Wales, and Northern Ireland, 2011; Haines et al., 2009; National Institute for Health and Clinical Excellence, 2008). The possible interpretation that walking is greater in central locations with shorter, more walkable, access to multiple destinations has evident implications for public health and urban planning policy given the objective to promote walking (and sustainability in travel) especially among middle aged and older adults. More objective measures of walking behaviour and perceptions of the environment should be included in future research.

\section{Contributorship statement}

TP generated the environmental variables and CT had access to the Whitehall II data. TP takes responsibility for the integrity of the data and accuracy of the data analyses. TP wrote the first full draft of the manuscript. PW and CT made suggestions on the content and structure of the manuscript. All authors contributed to subsequent drafts and critical revision of the manuscript.

\section{Acknowledgements}

Funding was provided by the UK Economic and Social Research Council (RES-064-27-0026) and the Greek State Scholarship Foundation (1117/29/08/2007). The funders had no role in the conduct of the research or preparation of the manuscript. We thank all participants of the Whitehall II study, as well as all Whitehall II research scientists, study and data managers and clinical and administrative staff who make the study possible. The UK Medical Research Council, British Heart Foundation, and the US National Institutes of Health (R01HL36310 and R01AG013196) have supported collection of data in the Whitehall II study. Finally, we would like to thank the two anonymous reviewers for their helpful comments.

\section{Appendix A. Supporting information}

Supplementary data associated with this article can be found in the online version at http://dx.doi.org/10.1016/j.healthplace.2014. 02.011 .

\section{References}

Annear, M.J., Cushman, G., Gidlow, B., 2009. Leisure time physical activity differences among older adults from diverse socioeconomic neighborhoods. Health Place 15, 482-490.

Ball, K., Jeffery, R.W., Crawford, D.A., Roberts, R.J., Salmon, J., Timperio, A.F., 2008 Mismatch between perceived and objective measures of physical activity environments. Prev. Med. 47, 294-298.

Ball, K., Timperio, A., Salmon, J., Giles-Corti, B., Roberts, R., Crawford, D., 2007. Personal, social and environmental determinants of educational inequalities in walking: a multilevel study. J. Epidemiol. Community Health 61, 108-114.

Bassett, D.R., Pucher, J., Buehler, R., Thompson, D.L., Crouter, S.E., 2008. Walking, cycling, and obesity rates in Europe, North America, and Australia. J. Phys. Act. Health 5, 795-814.

Bauman, A.E., Bull, F.C., 2007. Environmental Correlates of Physical Activity and Walking in Adults and Children: A Review of Reviews.

Bentley, R., Jolley, D., Kavanagh, A.M., 2010. Local environments as determinants of walking in Melbourne, Australia. Soc. Sci. Med. 70, 1806-1815.

British Medical Association, 2012. Healthy Transport=Healthy Lives. BMA, London

Cao, X.Y., Mokhtarian, P.L., Handy, S.L., 2009. Examining the impacts of residential self-selection on travel behaviour: a focus on empirical findings. Transp. Rev. 29, 359-395.

Cerin, E., Leslie, E., Owen, N., 2009. Explaining socio-economic status differences in walking for transport: an ecological analysis of individual, social and environmental factors. Soc. Sci. Med. 68, 1013-1020.

Chaix, B., Meline, J., Duncan, S., Merrien, C., Karusisi, N., Perchoux, C., Lewin, A., Labadi, K., Kestens, Y., 2013. GPS tracking in neighborhood and health studies: a step forward for environmental exposure assessment, a step backward for causal inference? Health Place 21, 46-51.

Chief Medical Officers of England, Scotland, Wales, and Northern Ireland, 2011 Start Active, Stay Active: A Report on Physical Activity for Health from the Four Home Countries' Chief Medical Officers. Department of Health, London

Cochrane, T., Davey, R.C., Gidlow, C., Smith, G.R., Fairburn, J., Armitage, C.J., Stephansen, H., Speight, S., 2009. Small area and individual level predictors of physical activity in urban communities: a multi-level study in Stoke on Trent England. Int. J. Environ. Res. Public Health 6, 654-677.

Coombes, E., Jones, A.P., Hillsdon, M., 2010. The relationship of physical activity and overweight to objectively measured green space accessibility and use. Soc. Sci. Med. 70, 816-822.

Cummins, S., Curtis, S., Diez-Roux, A.V., Macintyre, S., 2007. Understanding and representing 'place' in health research: a relational approach. Soc. Sci. Med. 65, $1825-1838$

Dalton, A.M., Jones, A.P., Panter, J.R., Ogilvie, D., 2013. Neighbourhood, route and workplace-related environmental characteristics predict adults' mode of travel to work. PLoS One 8, e67575.

Department for Communities and Local Government, 2007. Generalised Land Use Database Statistics for England 2005

Department for Transport, 2012. National Travel Survey: 2011, National Travel Survey Statistics. Department for Transport

Department for Transport, 2013. National Public Transport Access Node.

Department for Transport, Road Accident Statistics Branch, 2009. Road Accident Data, 2008 [computer file], Colchester, Essex.

ESRI, 2010. ArcGIS Desktop 10.

Foster, C., Hillsdon, M., Jones, A., Grundy, C., Wilkinson, P., White, M., Sheehan, B. Wareham, N., Thorogood, M., 2009. Objective measures of the environment and physical activity-results of the environment and physical activity study in English adults. J. Phys. Act. Health 6, S70-80.

Foster, C., Hillsdon, M., Thorogood, M., 2004. Environmental perceptions and walking in English adults. J. Epidemiol. Community Health 58, 924-928.

Giles-Corti, B., Broomhall, M.H., Knuiman, M., Collins, C., Douglas, K., Ng, K., Lange, A., Donovan, R.J., 2005a. Increasing walking: how important is distance to, attractiveness, and size of public open space? Am. J. Prev. Med. 28, 169-176.

Giles-Corti, B., Bull, F., Knuiman, M., McCormack, G., Van Niel, K., Timperio, A., Christian, H., Foster, S., Divitini, M., Middleton, N., Boruff, B., 2013. The influence of urban design on neighbourhood walking following residential relocation: longitudinal results from the RESIDE study. Soc. Sci. Med., 77; , pp. 20-30.

Giles-Corti, B., Donovan, R.J., 2002. The relative influence of individual, social and physical environment determinants of physical activity. Soc. Sci. Med. 54, 1793-1812. 
Giles-Corti, B., Timperio, A., Bull, F.C.L., Pikora, T.J., 2005b. Understanding physical activity environmental correlates: increased specificity for ecological models. Exerc. Sport Sci. Rev. 33, 175-181.

Haines, A., McMichael, A.J., Smith, K.R., Roberts, I., Woodcock, J., Markandya, A., Armstrong, B.G., Campbell-Lendrum, D., Dangour, A.D., Davies, M., Bruce, N., Tonne, C., Barrett, M., Wilkinson, P., 2009. Public health benefits of strategies to reduce greenhouse-gas emissions: overview and implications for policy makers. Lancet 374, 2104-2114.

Hamer, M., Kivimaki, M., Steptoe, A., 2012. Longitudinal patterns in physical activity and sedentary behaviour from mid-life to early old age: a substudy of the Whitehall II cohort. J. Epidemiol. Community Health 66, 1110-1115.

Hillsdon, M., Lawlor, D.A., Ebrahim, S., Morris, J.N., 2008. Physical activity in older women: associations with area deprivation and with socioeconomic position over the life course: observations in the British Women's Heart and Health Study. J. Epidemiol. Community Health 62, 344-350.

Jarrett, J., Woodcock, J., Griffiths, U.K., Chalabi, Z., Edwards, P., Roberts, I., Haines, A., 2012. Effect of increasing active travel in urban England and Wales on costs to the National Health Service. Lancet 379, 2198-2205.

Jones, A., Bentham, G., Foster, C., Hillsdon, M., Panter, J., 2007. Obesogenic Environments - Evidence Review, Foresight Tackling Obesities: Future Choices.

Kamphuis, C.B., Van Lenthe, F.J., Giskes, K., Huisman, M., Brug, J., Mackenbach, J.P. 2009. Socioeconomic differences in lack of recreational walking among older adults: the role of neighbourhood and individual factors. Int. J. Behav. Nutr. Phys. Act. 6, 1.

Kelly, F., Anderson, H.R., Armstrong, B., Atkinson, R., Barratt, B., Beevers, S., Derwent D., Green, D., Mudway, I., Wilkinson, P., 2011. The impact of the congestion charging scheme on air quality in London. Part 1. Emissions modeling and analysis of air pollution measurements. Res. Rep. Health Eff. Inst., 5-71

King, W.C., Belle, S.H., Brach, J.S., Simkin-Silverman, L.R., Soska, T., Kriska, A.M., 2005. Objective measures of neighborhood environment and physical activity in older women. Am. J. Prev. Med. 28, 461-469.

Kruger, J., Ham, S.A., Berrigan, D., Ballard-Barbash, R., 2008. Prevalence of transportation and leisure walking among U.S. adults. Prev. Med. 47, 329-334.

Lee, I.M., Buchner, D.M., 2008. The importance of walking to public health. Med. Sci. Sports Exerc. 40, S512-S518.

Li, F., Harmer, P.A., Cardinal, B.J., Bosworth, M., Acock, A., Johnson-Shelton, D. Moore, J.M., 2008. Built environment, adiposity, and physical activity in adults aged 50-75. Am. J. Prev. Med. 35, 38-46.

Lin, L., Moudon, A.V., 2010. Objective versus subjective measures of the built environment, which are most effective in capturing associations with walking? Health Place 16, 339-348.

Lindsey, C., Sheather, S., 2010. Variable selection in linear regression. Stata J. 10 650-669.

Lopez, R.P., Hynes, H.P., 2006. Obesity, physical activity, and the urban environment: public health research needs. Environ. Health 5, 25.

Macintyre, S., 2007. Deprivation amplification revisited; or, is it always true that poorer places have poorer access to resources for healthy diets and physical activity? Int. J. Behav. Nutr. Phys. Act. 4, 32

Macintyre, S., Ellaway, A., Cummins, S., 2002. Place effects on health: how can we conceptualise, operationalise and measure them? Soc. Sci. Med. 55, 125-139.

Marmot, M., Brunner, E., 2005. Cohort profile: the Whitehall II study. Int. J. Epidemiol. 34, 251-256.

Mitchell, R.J., Popham, F., 2008. Effect of exposure to natural environment on health inequalities: an observational population study. Lancet 372, 1655-1660.

Mytton, O.T., Townsend, N., Rutter, H., Foster, C., 2012. Green space and physical activity: an observational study using Health Survey for England data. Health Place 18, 1034-1041.
National Institute for Health and Clinical Excellence, 2008. Promoting and Creating Built or Natural Environments that Encourage and Support Physical Activity. National Institute for Health and Clinical Excellence, London

Noble, M., Wright, G., Dibben, C., Smith, G.A.N., McLennan, D., Anttila, C., Barnes, H., Mokhtar, C. Noble, S., Avenell, D., Gardner, J., Covizzi, I., Lloyd, M., 2004. The English Indices of Deprivation 2004: Report to the Office of the Deputy Prime Minister. Neighbourhood Renewal Unit, London

Office for National Statistics, 2001. n.d. Neighbourhood Statistics - Population Density (UV02).

Ogilvie, D., Mitchell, R.J., Mutrie, N., Petticrew, M., Platt, S., 2008. Personal and environmental correlates of active travel and physical activity in a deprived urban population. Int. J. Behav. Nutr. Phys. Act. 5, 43.

Ordnance Survey, 2013. OS OpenData ${ }^{\mathrm{TM}}$

Panter, J., Griffin, S., Dalton, A.M., Ogilvie, D., 2013. Patterns and predictors of changes in active commuting over 12 months. Prev. Med. 57, 776-784.

Panter, J.R., Jones, A.P., 2008. Associations between physical activity, perceptions of the neighbourhood environment and access to facilities in an English city. Soc. Sci. Med. 67, 1917-1923.

Poortinga, W., 2006. Perceptions of the environment, physical activity, and obesity. Soc. Sci. Med. 63, 2835-2846.

Priyantha Wedagama, D.M., Bird, R.N., Metcalfe, A.V., 2006. The influence of urban land-use on non-motorised transport casualties. Accid. Anal. Prev. 38, 1049-1057.

Rothman, K.J., Greenland, S., Lash, T.L., 2008. Validity in epidemiologic studies. In: Rothman, K.J., Greenland, S., Lash, T.L. (Eds.), Modern Epidemiology, 3rd ed. Lippincott Williams \& Wilkins, Philadelphia, pp. 128-147

Saelens, B.E., Sallis, J.F., Black, J.B., Chen, D., 2003. Neighborhood-based differences in physical activity: an environment scale evaluation. Am. J. Public Health 93, $1552-1558$.

Schuurman, N., Cinnamon, J., Crooks, V.A., Hameed, S.M., 2009. Pedestrian injury and the built environment: an environmental scan of hotspots. BMC Public Health 9, 233.

Sebert Kuhlmann, A.K., Brett, J., Thomas, D., Sain, S.R., 2009. Environmental characteristics associated with pedestrian-motor vehicle collisions in Denver, Colorado. Am. J. Public Health 99, 1632-1637.

Smith, G., Gidlow, C., Davey, R., Foster, C., 2010. What is my walking neighbourhood? A pilot study of English adults' definitions of their local walking neighbourhoods. Int. J. Behav. Nutr. Phys. Act. 7, 34.

Spittaels, H., Foster, C., Oppert, J.-M., Rutter, H., Oja, P., Sjostrom, M., De Bourdeaudhuij, I., 2009. Assessment of environmental correlates of physical activity: development of a European questionnaire. Int. J. Behav. Nutr. Phys. Act. 6, 39 .

Taylor, H.L., Jacobs , D.R., Schucker, B., Knudsen, J., Leon, A.S., Debacker, G., 1978. A questionnaire for the assessment of leisure time physical activities. J. Chronic Dis. $31,741-755$.

The Chief Medical Officer, 2004. At Least Five a Week: Evidence on the Impact of Physical Activity and its Relationship to Health. Department of Health, London

Turrell, G., Haynes, M., Wilson, L.A., Giles-Corti, B., 2013. Can the built environment reduce health inequalities? A study of neighbourhood socioeconomic disadvantage and walking for transport. Health Place 19, 89-98.

Van Dyck, D., Cardon, G., Deforche, B., Sallis, J.F., Owen, N., De Bourdeaudhuij, I., 2010. Neighborhood SES and walkability are related to physical activity behavior in Belgian adults. Prev. Med. 50 (Suppl 1), S74-S79.

World Health Organization, 2010. Global Recommendations on Physical Activity for Health. WHO, Geneva, Switzerland 